EPJ Web of Conferences 106, 02015 (2016)

DOI: $10.1051 /$ epjconf/201610602015

(C) Owned by the authors, published by EDP Sciences, 2016

\title{
FLUOLE-2: An Experiment for PWR Pressure Vessel Surveillance
}

\author{
Nicolas Thiollay ${ }^{1}$, Jacques Di Salvo ${ }^{1}$, Charlotte Sandrin ${ }^{2}$, Michel Soldevila ${ }^{3}$, Stéphane Bourganel ${ }^{3}$, \\ Clément Fausser ${ }^{1}$, Christophe Destouches ${ }^{1}$, Patrick Blaise ${ }^{1}$, Christophe Domergue ${ }^{1}$, Hervé Philibert ${ }^{1}$, \\ Jonathan Bonora $^{1}$, Adrien Gruel ${ }^{1}$, Benoit Geslot ${ }^{1}$, Vincent Lamirand ${ }^{1}$, Alexandra Pepino ${ }^{1}$, \\ Alain Roche ${ }^{1}$, Olivier Méplan ${ }^{4}$, and Mourad Ramdhane ${ }^{4}$ \\ ${ }^{1}$ CEA/DEN Cadarache, SPEx, 13108 Saint Paul lez Durance, France \\ ${ }^{2}$ EDF/SEPTEN, 12-14 avenue Dutriévoz, 69628 Villeurbanne, France \\ ${ }^{3}$ CEA/DEN Saclay, SERMA, 91191 Gif-sur-Yvette Cedex, France \\ ${ }^{4}$ CNRS/IN2P3/LPSC, 53 avenue des Martyrs, 38026 Grenoble, France
}

\begin{abstract}
FLUOLE-2 is a benchmark-type experiment dedicated to 900 and $1450 \mathrm{MWe}$ PWR vessels surveillance dosimetry. This two-year program started in 2014 and will end in 2015. It will provide precise experimental data for the validation of the neutron spectrum propagation calculation from core to vessel. It is composed of a square core surrounded by a stainless steel baffle and internals: PWR barrel is simulated by steel structures leading to different steel-water slides; two steel components stand for a surveillance capsule holder and for a part of the pressure vessel. Measurement locations are available on the whole experimental structure. The experimental knowledge of core sources will be obtained by integral gamma scanning measurements directly on fuel pins. Reaction rates measured by calibrated fission chambers and a large set of dosimeters will give information on the neutron energy and spatial distributions. Due to the low level neutron flux of EOLE ZPR a special, high efficiency, calibrated gamma spectrometry device will be used for some dosimeters, allowing to measure an activity as low as $7.10^{-2} \mathrm{~Bq}$ per sample. ${ }^{103 m} \mathrm{Rh}$ activities will be measured on an absolute calibrated X spectrometry device. FLUOLE-2 experiment goal is to usefully complete the current experimental benchmarks database used for the validation of neutron calculation codes. This two-year program completes the initial FLUOLE program held in 2006-2007 in a geometry representative of 1300 MWe PWR.
\end{abstract}

\section{Introduction}

In order to reduce margins and meet the Safety Bodies requirements, the lifetime extension of nuclear power plants requires the enhancement and the precise quantification of the fluence calculation at pressure vessel. This calculation must be qualified not only at the vessel hot spot but also at any point where metallurgical defect may be detected.

FLUOLE-2 program, acronym of FLUency in eOLE, carried out in the critical facility EOLE [1] at the French CEA Cadarache Centre, is a benchmark-type experiment dedicated to the qualification of neutron spectrum propagation calculation outside the core to both surveillance capsule and

This is an Open Access article distributed under the terms of the Creative Commons Attribution License 2.0, which permits unrestricted use, distribution, and reproduction in any medium, provided the original work is properly cited. 


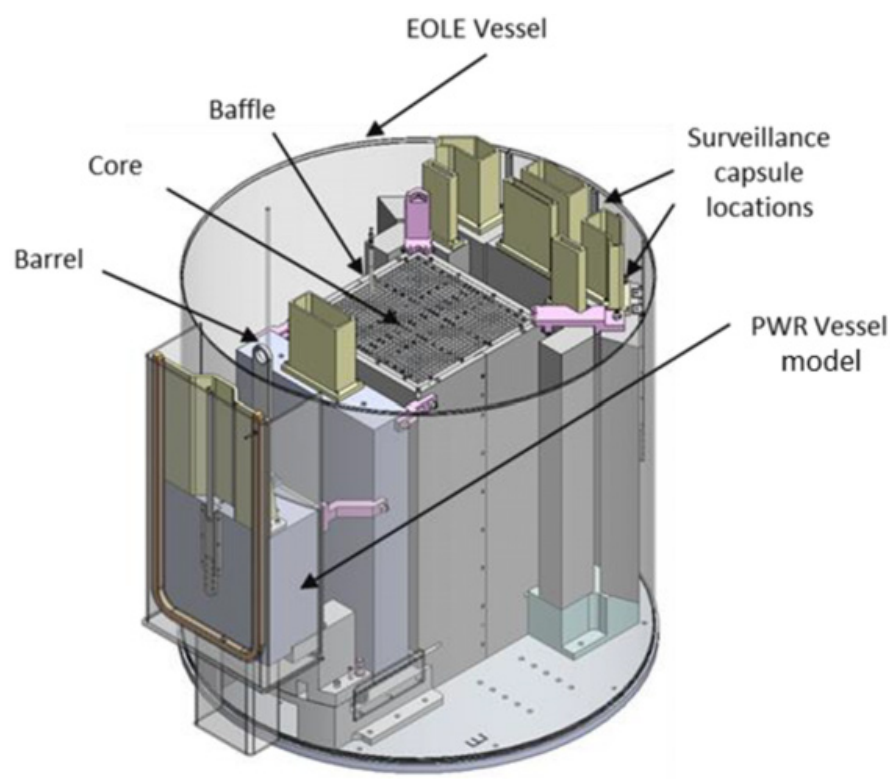

Figure 1. General design of FLUOLE-2 experimental core.

pressure vessel. Several steel-water slides simulate neutron paths in both 900 and 1450 MWe PWRs. This program has been designed using the feedback of FLUOLE program [2] held in 2006-2007 in a geometry simulating a 1300 MWe PWR. Measurement uncertainties will be reduced thanks to lower tolerances to manufacturing. Moreover, FLUOLE-2 program uses both $\mathrm{UO}_{2}$ and $\mathrm{MOX}$ fuels to discriminate $\mathrm{U}$ and $\mathrm{Pu}$ contributions to the fast neutron fluence at both surveillance capsule and vessel. FLUOLE and FLUOLE-2 experiments may be considered as half-analytical benchmarks, at half way between a pure analytical one and an industrial situation.

Experimental structure has been designed to stand for specific industrial configurations. Measurements will be carried out from mid-2014 to the end 2015. Different measurements techniques are implemented for the acquisition of the data to be used, i) for the analysis of sources distribution in the core, ii) for the study of neutron spectrum at an important number of locations in core, reflector, internals, as in front and behind the (simulated) vessel.

A particular care has been taken in measurement techniques in order to minimize measurement uncertainties; indeed low uncertainties values are necessary to allow enhancement of calculation schemes by discriminating the different effects impacting biases and uncertainties of calculated results.

\section{Experimental Core Configurations}

EOLE critical facility, in which FLUOLE-2 program has been implemented, is composed of a concrete structure offering biological shielding and a cylindrical vessel in aluminium with an over structure in stainless steel. EOLE is able to contain various types of core structures, and a water loop coupled with a thermoregulation station. During the experimental program, water temperature will be maintained at $20 \pm 0.1^{\circ} \mathrm{C}(1 \sigma)$.

The general design of experimental device is presented on Fig. 1.

The core is a $29 \times 29$ pins square lattice with a $1.42 \mathrm{~cm}$ pitch controlled by four control rods and one pilot rod. $\mathrm{UO}_{2}$ fuel pins are $3.7 \%$ enriched in ${ }^{235} \mathrm{U}$. MOX fuel pins contain $7 \%$ of fissile $\mathrm{Pu}$. They both are $80 \mathrm{~cm}$ high, have a Zy4 cladding and an aluminium over-cladding (Fig. 2). 


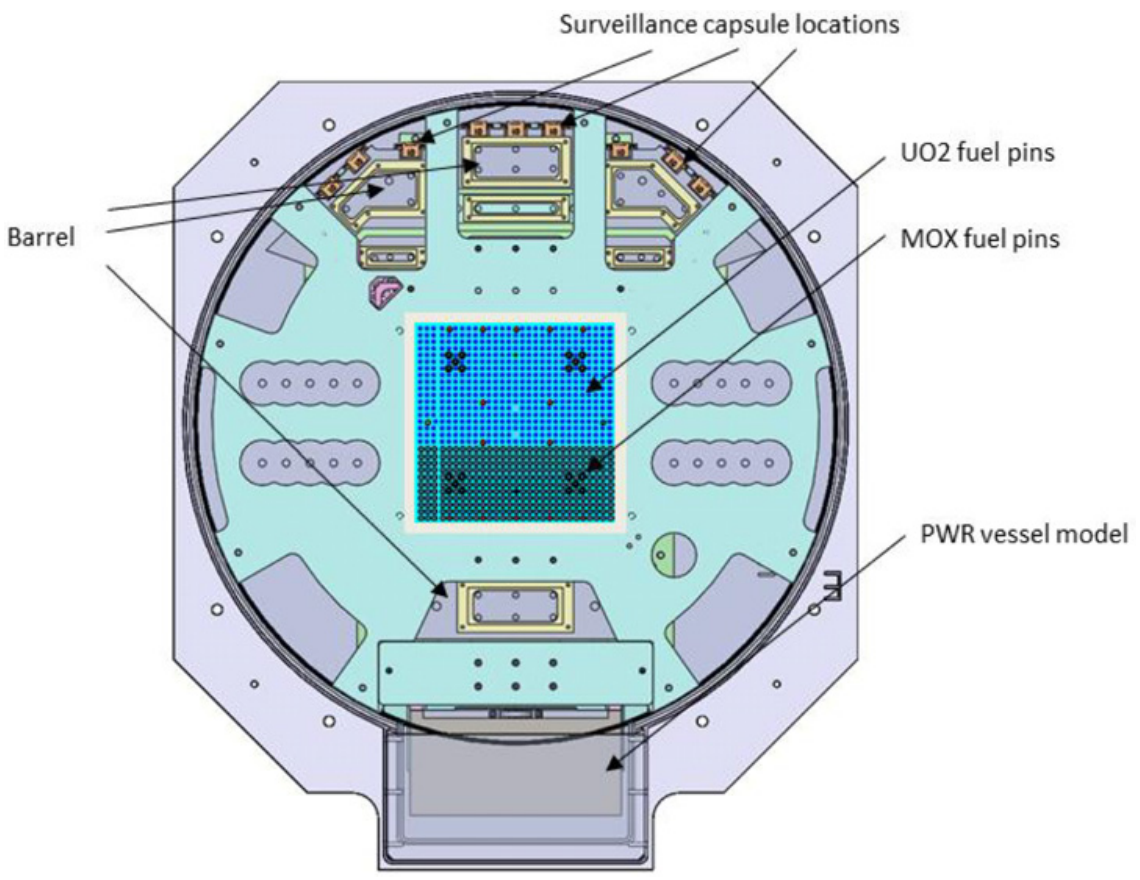

Figure 2. UO2 and MOX fuels loading pattern.

The $2.86 \mathrm{~cm}$ thick stainless steel baffle is representative of PWRs ones. The barrel is made of rectangular stainless steel sectors with various thicknesses. This design allows to reproduce a large number of situations encountered in 900 and 1450 MWe PWRs between core and internals.

Nine pieces of stainless steel are fixed on one side of the core: they stand for surveillance capsule holders. Another stainless steel piece is added to stand for a part of a PWR pressure vessel which allows dosimetry measurements inside and outside of pressure vessel.

The difference on the water temperature between a PWR and EOLE has been taken into account in order to ensure the mock-up representativeness. Reduction of the water gap is obtained by surrounding fuel pins with aluminum over clads.

Four grids, held by tie rods, ensure the whole device stiffness and experimental locations accuracy. Design, manufacturing, assembling and a special metrology allow to know distances in the three directions with an accuracy better than $0.1 \mathrm{~mm}$ at almost all positions. Two campaigns of metrology have been done, the first one directly on structures after manufacturing and the second one in-situ in EOLE; to ensure the precision of machining and to guarantee distances between structures.

Plutonium and uranium contributions to the fast fluence at both vessel and surveillance capsules locations will be discriminated. The number of available MOX fuel pins does not allow to get a $100 \%$ MOX critical core. Consequently, a $\mathrm{UO}_{2}-\mathrm{MOX}$ core has been conceived.

In a first stage, MOX fuel pins face the stainless steel piece standing for a PWR vessel while $\mathrm{UO}_{2}$ fuel pins face the surveillance capsule locations. In a second stage, $\mathrm{UO}_{2}$ and $\mathrm{MOX}$ pins are swapped to discriminate $\mathrm{U}$ and $\mathrm{Pu}$ contributions. Swapping $\mathrm{U}$ and Pu fuels instead of moving capsule holders, vessel model and steel structures ensures that distances between pieces keep constant from one configuration to another. This choice, which minimizes experimental uncertainties, proceeds directly from the feedback of FLUOLE program. 


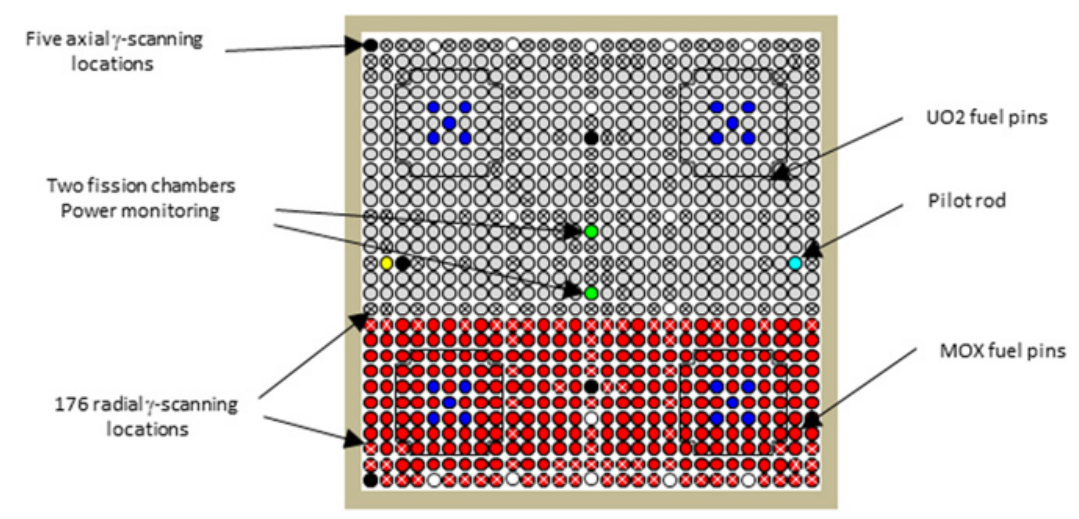

Figure 3. Location of fuel pins in the radial power map.

\section{Core Source Measurements}

Integral gamma scanning is performed on fuel pins so that useful experimental data are available for the qualification of core sources calculation. Two kinds of distributions are explored: a radial map at core mid-plane and an axial one.

\subsection{Radial Power Map}

After a 20 minutes irradiation at generally $30 \mathrm{~W}$, up to 25 pins are withdrawn. 22 of them are placed on an automatic holder in front of a HPGe spectrometry device leading to integrate the whole gamma spectrum above $550 \mathrm{keV}$ emitted by a $70 \mathrm{~mm}$ wide area at the middle of each pin fissile stack. Prior to irradiation, each pin is measured on the same device in order to subtract the background from the post irradiation measurement. The last three pins are placed on a special spectrometry device to monitor global activity decay during measurement process.

Eight measurement campaigns will be performed to explore 176 locations (70 MOX pins and 106 $\mathrm{UO}_{2}$ pins) indicated by crosses on Fig. 3. Results will be normalized to the mean values of three pins of same compositions in order to get a relative fission rate distribution. Both maps will be rescaled together is order to get a homogenized power distribution within the core. The normalization is made using a particular gamma peak from a common fission product. The complete process is described in [3].

Locations are chosen to obtain power distributions near dosimetry positions in the core and also at the edges of the fuel, facing measurement positions in capsule holders and in the pressure vessel. Other locations are selected at the $\mathrm{UO}_{2} / \mathrm{MOX}$ border to qualify the source distribution at this interface. Precise knowledge of sources distribution is a key point for the qualification of both reflector effect and fast neutron propagation through PWR internals.

\subsection{Axial Power Map}

Axial buckling represents a useful data for the qualification of a 3D core calculation. Axial power distributions will be measured on five pins, two MOX and three $\mathrm{UO}_{2}$ fuel pins (full black on Fig. 3) positioned either at two corners or inside core positions in order not to be perturbed by the U/Pu frontier.

As for radial power distributions, two pins are withdrawn: the first one is placed on a gamma spectrometry device and is automatically moved axially in front of a $10 \mathrm{~mm}$ wide window while the other one is used for monitoring total spectrum decay. Uncertainties on normalized activity distribution are roughly $1 \%(2 \sigma)$ at the middle of the pin and $2 \%$ at edges. 


\section{$15^{\text {th }}$ ISRD}
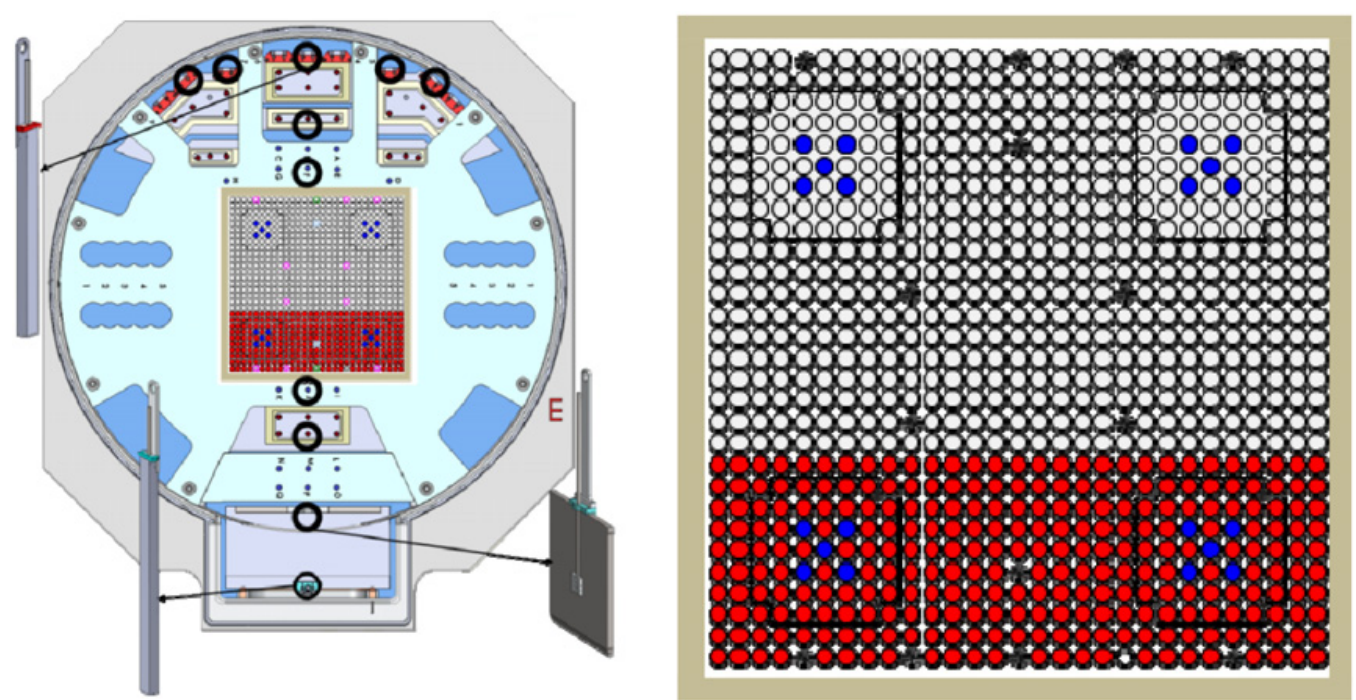

Figure 4. Location of the ${ }^{235} \mathrm{U},{ }^{238} \mathrm{U}$ and ${ }^{237} \mathrm{~Np}$ fission chambers measurements.

\section{Neutron Spectrum Propagation Measurements}

Two experimental techniques, fission chambers and dosimeters, have been implemented in order to get information on the largest possible energy range of the neutron spectrum inside and outside the core. These measurements are only performed at core mid-plane. A particular attention is paid on the specific azimuths having special interest for the calculation of PWR surveillance program dosimetry:

- The direction from core centre to the piece modelling vessel (common to 900 and $1450 \mathrm{MWe}$ PWRs),

- The directions from core centre to capsule holders for both 900 and 1450 MWe PWRs.

\subsection{Fission Reaction Rate Measurement}

Fission rate measurements are implemented using three types of $8 \mathrm{~mm}$ diameter fission chambers with ${ }^{235} \mathrm{U},{ }^{237} \mathrm{~Np}$ and ${ }^{238} \mathrm{U}$ deposits. Fission chambers are positioned axially at core mid-plane inside an aluminium over-cladding filled with air. Inside the core, fission chambers are inserted in locations (symbolized by crosses inside the core and circles outside on Fig. 4) devoted to measurements and not substituting fuel pins.

All measurements are monitored and normalized to two calibrated reference ${ }^{235} \mathrm{U}$ fission chambers located at fixed places inside the core [4].

Uncertainty on the fission rate relative maps is about $2 \%(2 \sigma)$.

EOLE flux level is very low outside the core, especially in the capsule and the pressure vessel locations. Fabrication of specific fission chambers with adapted masses of deposits combined to irradiations performed at $800 \mathrm{~W}$ for several hours enables measurements inside capsule holders and behind the steel piece simulating the pressure vessel.

However, the monitoring of EOLE thanks to ${ }^{235} \mathrm{U}$ fission chambers placed in the core requires small amounts of deposits. Counting rates on ${ }^{235} \mathrm{U}$ will be high in these locations where the neutron flux is high. 
Table 1. Characteristics of activation dosimeters used in FLUOLE-2 program.

\begin{tabular}{|c|c|c|c|c|c|}
\hline Material & Gold & Cobalt & Tin & Rhodium & Indium \\
\hline Reaction & ${ }^{197} \mathrm{Au}(\mathrm{n}, \gamma)^{198} \mathrm{Au}$ & ${ }^{59} \mathrm{Co}(\mathrm{n}, \gamma)^{60} \mathrm{Co}$ & ${ }^{117} \mathrm{Sn}\left(\mathrm{n}, \mathrm{n}^{\prime}\right)^{117 m} \mathrm{Sn}$ & ${ }^{103} \mathrm{Rh}\left(\mathrm{n}, \mathrm{n}^{\prime}\right)^{103 m} \mathrm{Rh}$ & ${ }^{115} \mathrm{In}\left(\mathrm{n}, \mathrm{n}^{\prime}\right)^{115 m} \mathrm{In}$ \\
\hline Threshold (MeV) [5] & $\mathrm{Th}+$ epi & Th + epi & 0.3 & 0.69 & 1.3 \\
\hline Half-life & 2.7 days & 5.3 years & 14.0 days & 56 minutes & $4.5 \mathrm{hours}$ \\
\hline Foil diameter & $8 \mathrm{~mm}$ & $8 \mathrm{~mm}$ & $8 \mathrm{~mm}$ & $8 \mathrm{~mm}$ & $8 \mathrm{~mm} / 29 \mathrm{~mm}$ \\
\hline Foil thickness & $50 \mu \mathrm{m}$ & $2 \mathrm{~mm}$ & $0.5 \mathrm{~mm}$ & $50 \mu \mathrm{m}$ & $1 \mathrm{~mm}$ \\
\hline
\end{tabular}

\begin{tabular}{|c|c|c|c|c|c|}
\hline Material & Nickel & Iron & Titanium & Aluminium & Vanadium \\
\hline Reaction & ${ }^{58} \mathrm{Ni}(\mathrm{n}, \mathrm{p})^{58} \mathrm{Co}$ & ${ }^{54} \mathrm{Fe}(\mathrm{n}, \mathrm{p})^{54} \mathrm{Mn}$ & ${ }^{46} \mathrm{Ti}(\mathrm{n}, \mathrm{p})^{46} \mathrm{Sc}$ & ${ }^{27} \mathrm{Al}(\mathrm{n}, \alpha)^{24} \mathrm{Na}$ & ${ }^{51} \mathrm{~V}(\mathrm{n}, \alpha)^{48} \mathrm{Sc}$ \\
\hline Threshold $(\mathrm{MeV})[5]$ & 2.7 & 2.8 & 4.4 & 7.3 & 11.5 \\
\hline Half-life & 70 days & 312 days & 84 days & 15 hours & 43.7 hours \\
\hline Foil diameter & $8 \mathrm{~mm} / 29 \mathrm{~mm}$ & $8 \mathrm{~mm} / 29 \mathrm{~mm}$ & $8 \mathrm{~mm}$ & $8 \mathrm{~mm}$ & $8 \mathrm{~mm}$ \\
\hline Foil thickness & $3 \mathrm{~mm}$ & $3 \mathrm{~mm}$ & $3 \mathrm{~mm}$ & $3 \mathrm{~mm}$ & $3 \mathrm{~mm}$ \\
\hline
\end{tabular}

\subsection{Activation Dosimeters}

A large set of dosimeters has been selected on the basis of their energy responses, cross section levels and half-lives. Their characteristics are shown in Table 1.

About 600 dosimeters will be irradiated throughout 8 irradiations lasting from 4 to 5 hours at an EOLE power of $200 \mathrm{~W}$ or $800 \mathrm{~W}$. Every campaign is monitored by eight detectors:

- Two calibrated reference ${ }^{235} \mathrm{U}$ fission chambers to give irradiation power level and to record its stability.

- Six dosimeters (gold, cobalt and nickel) placed at two fixed reference positions inside the core. Dosimeters are placed inside special containments made of aluminium for both core and water locations and of stainless steel for locations in internal structures. Containments are set at the mid-plane of the fissile stack. Free spaces are filled with:

- Aluminium for core locations.

- Water for reflector locations.

- Stainless steel for internals structures locations.

The diameter of dosimeters foils ranges from $8 \mathrm{~mm}$ for locations in the core, water, steel structures to $29 \mathrm{~mm}$ for positions in capsule holders and the stainless steel modelling the pressure vessel. Their thicknesses can reach $3 \mathrm{~mm}$ for detectors with high energy threshold. Theses sizes are made necessary to get enough counting rates after irradiations in low flux levels. Specific foil holders will maintain largest dosimeters.

Figure 5 shows measurement locations along neutron propagation. Fourteen positions are also investigated inside the core. Due to the short half-life of activation products, a special recovery process has been set up to enable measurements in order to start as soon as possible after the reactor shut down.

Even with experiments performed at $800 \mathrm{~W}$, the activities of some dosimeters still remain very low. These dosimeters will be measured thanks to two recent high efficiency HPGe detectors equipping the MADERE platform [6]. About 100 to 150 dosimeters require to be measured on a special spectrometry device designed by the French National Research Centre CNRS/IN2P3/LPSC ${ }^{1}$ laboratory in Grenoble [7]. The high efficiency HPGe detector is surrounded by a lead shield which internal part is made of archaeological lead in order to cut off bremsstrahlung rays. The detector and the shield are placed inside an extra active shielding made of scintillators, which stops the counting when cosmic rays are detected. Thanks to all these precautions, the background level is 0.06 counts per second, close to activities expected at around $7 \cdot 10^{-2} \mathrm{~Bq}$. The background level corresponds to gamma rays emitted in the $[30 \mathrm{keV}-3 \mathrm{MeV}]$ range whereas activities measurements correspond to gamma rays emitted at

\footnotetext{
${ }^{1}$ Centre National de la Recherche Scientifique, Institut National de Physique Nucléaire et de Physique des Particules, Laboratoire de Physique Subatomique et de Cosmologie, 53 rue des Martyrs, 38026 Grenoble Cedex, France
} 


\section{$15^{\text {th }}$ ISRD}

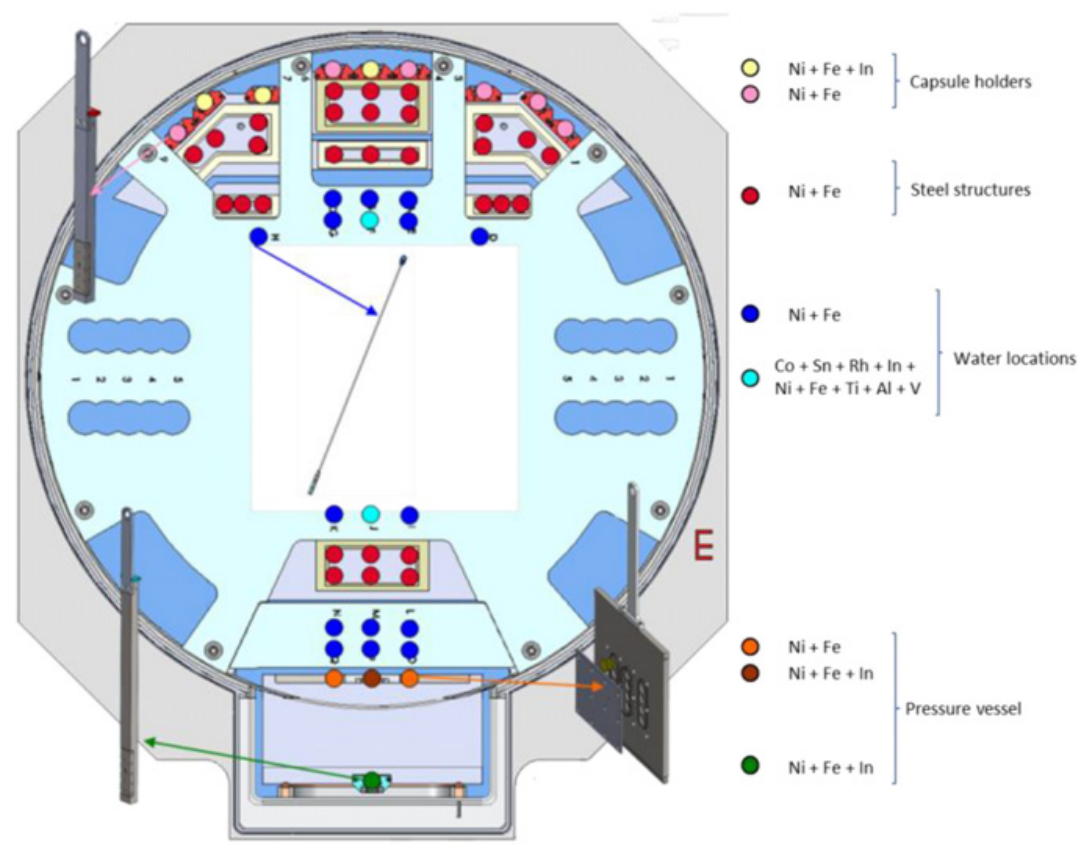

Figure 5. Measurement locations of dosimeters foils.

$834 \mathrm{keV}\left({ }^{54} \mathrm{Mn}\right)$. This makes possible to obtain activities measured with a maximum uncertainty of $7 \%$ $(1 \sigma)$.

The activities of other dosimeters, except rhodium, will be measured on three usual HPGe counting devices. The activity of ${ }^{103 \mathrm{~m}} \mathrm{Rh}, \mathrm{X}$ emitter, has to be measured on a LeGe detector.

\section{Conclusion}

The aim of FLUOLE-2 experimental program, acronym of FLUency in eOLE, is to validate neutron propagation calculation from core source to surveillance capsule and pressure vessel in geometries representative of both 900 MWe and 1450 MWe French PWRs. This experiment completes the former FLUOLE experimental program, held in 2006-2007, and dedicated to $1300 \mathrm{MWe}$.

The core loading pattern is made of a regular square $\mathrm{UO}_{2}$ and MOX fuels lattice which will allow discriminating $\mathrm{U}$ and $\mathrm{Pu}$ contributions to the fast neutron fluence at the vessel.

The core source is determined using integral gamma spectrometry on $\mathrm{UO}_{2}$ and $\mathrm{MOX}$ fuel pins. This source is also characterized by complementary measurements on fourteen locations involving ${ }^{235} \mathrm{U},{ }^{238} \mathrm{U}$ and ${ }^{237} \mathrm{~Np}$ fission chambers and dosimeters with thresholds ranging from thermal energies up to $11 \mathrm{MeV}$.

Various water-steel slides are positioned between the core and two specific devices to simulate surveillance capsule holders and both the inner and outer faces of pressure vessel.

Ten types of dosimeters with various energy responses are irradiated outside the core. Indium dosimeters with a $1.3 \mathrm{MeV}$ threshold placed on the both faces of pressure vessel locations allow to determine the neutron population involved in vessel embrittlement.

The large set of experimental results may contribute to discriminate the origin of possible discrepancies between calculation and measurement on parameters such as cross-sections (iron, water) or fission spectrum shape.

Measurements are scheduled from June 2014 to the end of 2015. 
The authors acknowledge EDF for supporting this work and the team in charge of exploitation and experimentation at EOLE facility.

\section{References}

[1] J.-C. Bosq, M. Antony, J. Di Salvo, J.-C. Klein, N. Thiollay, P. Blaise, P. Leconte, The Use of EOLE and MINERVE Critical Facilities for the Generation 3 Light Water Reactor Studies, Proc. Int. Conf. ICAPP, Nice, France, May 2-5, 2011

[2] D. Beretz, S. Bourganel, P. Blaise, C. Destouches, N. Huot, J-M. Girard and al, FLUOLE : A new relevant experiment for PWR pressure vessel surveillance, Proc. Int. Conf. ISRD 13, Akersloot, Netherlands, May 25-29, 2008

[3] P. Blaise, S. Cathalau, N. Thiollay, P. Fougeras, V. Laval, H. Philibert, JP. Hudelot, Fission Products Particular Peak measurement for UO2-Gd2O3-MOX $\gamma$-scanning renormalization in 100\% MOX ABWR mock-up cores, Proceedings of ICONE12, Proc. of the 12th International Conference on Nuclear Engineering, Arlington, Virginia USA, April 25-29, 2004

[4] V. Lamirand, B. Geslot, J. Wagemans, L. Borms, E. Malambu, P. Casoli, X. Jacquet, G. Rousseau, G. Grégoire, P. Sauvecane, D. Garnier, S. Bréaud, F. Mellier, J. Di Salvo, C. Destouches, P. Blaise, Miniature fission chambers calibration in pulse mode: interlaboratory comparison at the SCK $\bullet C E N$ BRI and CEA CALIBAN reactors, Proceedings of ANIMMA, Marseille France, June 23-27, 2013

[5] J.H. Baard, W.L. Zijp, H.J. Nolthenius, Nuclear Data Guide for Reactor Neutron Metrology, ISBN 0-7923-0486-1, Kluwer Academic Publishers, 1989

[6] V. Sergeyeva, C. Domergue, C. Destouches, J-M. Girard, H. Philibert, J. Bonora, N. Thiollay, Improvements on low level activity gamma measurements and X-ray spectrometry at the CEAMADERE measurement platform, Proceedings of ISRD 15, Aix en Provence, France, May 18-23, 2014

[7] A. Berabeb and R. Brissot, ISN 96.12, Ipsc.in2p3.fr/ 